\title{
PERSPECTIVAS ONTOLÓGICAS DOS GAMES NO SÉCULO XXI
}

\author{
Ontological perspectives of the games in the 21 st century
}

\author{
Perspectivas ontológicas de los juegos en el siglo XXI
}

Luís Carlos Petry ${ }^{1}$

Fig. 1 - Games e metaversos entre Myst e Bioshock, por Luís Carlos Petry, 2011

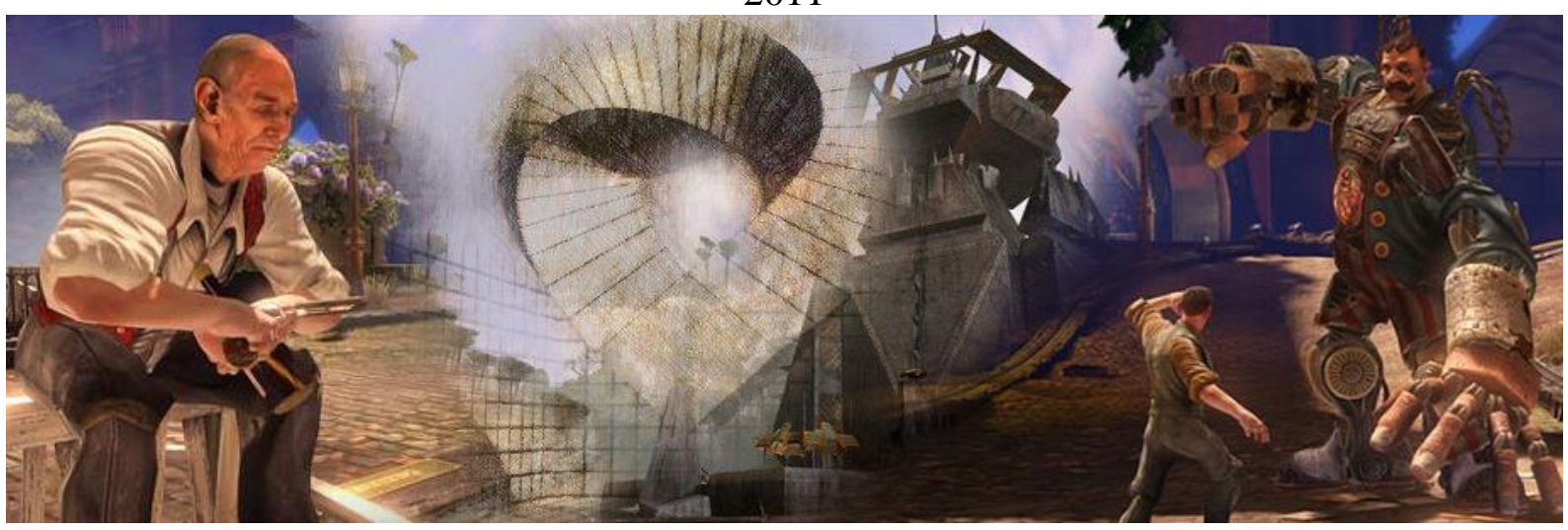

\section{Resumo}

A presente proposta situa-se em um processo de pesquisa que vem sendo desenvolvido no PPG da PUCSP, Tecnologias da Inteligência e Design Digital, dentro do qual investigamos, conjuntamente com nossos orientandos e outros colegas, as relações existentes entre o conceito de desenvolvimento de games e metaversos, com as inúmeras discussões e contextualizações realizadas por pesquisadores do digital no que tange a presença de conceitos ontológicos em sua constituição e processo ${ }^{2}$. Situamos o conceito de ontologia digital e sua incidência na pesquisa dos metaversos e games. Apresentamos algumas ideias

\footnotetext{
${ }^{1}$ Pesquisador e professor no Programa de Pós-graduação em Tecnologias da Inteligência e Design Digital (MD) da Pontifícia Universidade Católica de São Paulo, Brasil (PUCSP). Formação em Filosofia Hermenêutica com Ernildo Stein (UFRGS/PUCRS). Formação em psicanálise no Centro de Estudos Freudianos do Brasil. Doutor em Comunicação e Semiótica (2003), pelo Programa de Pós-graduação em Comunicação e Semiótica da PUCSP. Pesquisador do NuPHG, Núcleo de Pesquisa em Hipermídia e Games da PUCSP. Autor do Projeto do Curso Superior de Tecnologia em Jogos Digitais da PUCSP. Consultor para assuntos games e hipermídia da FTC (Portugal). Mantém o site de Pesquisa: http://www.topofilosofia.net. E-mails: petry@pucsp.br e alletsator@gmail.com

${ }^{2} \mathrm{O}$ presente artigo retoma de forma ligeiramente modificada parte dos temas de um outro anterior, intitulado Por uma ontologia dos metaversos e games, de 2010, resinificando seu campo de aplicação formal sobre objetos específicos no universo dos games. O aplicativo em Unity 3D que foi construído para a sua apresentação no GamePad 2011, pode ser consultada e baixada em: http://www.topofilosofia.net/ unity3d/GamePad2011.
} 
normativas sobre a questão, relacionando-as a proposta de uma análise que leve em conta os pressupostos ontológicos que estão presentes na conceitualização e no desenvolvimento de um game. A partir de uma delimitação provisória do conceito de Worldbuilding (enquanto conceito de formação de mundo no campo dos games) organiza os dois casos modelos. Finalmente, indica a importância que um pensar orientado ontologicamente pode desempenhar, não somente para uma compreensão mais contextualizada dos games e metaversos, mais igualmente para aqueles que se engajam em seus processos de concepção e desenvolvimento.

Palavras-chave: game, metaverso, ontologia, topofilosofia, Myst, Bioshock.

\begin{abstract}
The proposal lies in a research process that is being developed at PPG PUCSP, Intelligence and Design Digital Technologies, within which we investigate, together with our mentees and other colleagues, the relationship between the concept of game development and metaverse, with the numerous discussions and contextualization made by digital researchers regarding the presence of ontological concepts in its constitution and process. We situate the concept of digital ontology and its impact on research of metaverses and games. We present some normative ideas on the issue, relating them to draft an analysis that takes into account the ontological assumptions that are present in the conceptualization and development of a game. From a provisional definition of the concept of Worldbuilding (as a concept in the world of training in the games field) organizes both cases models. Finally, it indicates the importance that an ontologically oriented thinking can play not only for a more contextualized understanding of games and metaverses plus also for those who are engaged in their design and development processes.
\end{abstract}

Keywords: game, metaverse, ontology, topophilosophy, Myst, Bioshock.

\title{
Resumen
}

La presente propuesta se encuentra en un proceso de investigación que se está desarrollando en PPG PUCSP, Inteligencia y Diseño Digital Technologies, dentro de los cuales se investiga, junto con nuestros aprendices y otros colegas, la relación entre el concepto de desarrollo de juegos y metaverso, con las numerosas discusiones y contextualización de los investigadores digitales en cuanto a la presencia de conceptos ontológicos en su constitución y proceso. Nos situamos el concepto de ontología digital y su impacto en la investigación de los metaversos y juegos. Presentamos algunas ideas normativas sobre el tema, relacionándolos con la 
elaboración de un análisis que tenga en cuenta los supuestos ontológicos que están presentes en la conceptualización y el desarrollo de un juego. A partir de una definición provisional del concepto de worldbuilding (como un concepto en el mundo de la formación en el campo de juegos) organiza ambos modelos casos. Por último, indica la importancia de que un pensamiento orientado ontológicamente puede jugar no sólo para una comprensión más contextualizada de juegos y metaversos además también para aquellos que están involucrados en sus procesos de diseño y desarrollo.

Palabras-clave: juego, metaverso, ontología, topofilosofia, Myst, Bioshock.

\section{INTRODUÇÃO}

Fig.2 - Esquema de Células Ontológicas para uma Modelagem de Cena.

Ambiente Hause, Luís Carlos Petry 2011.

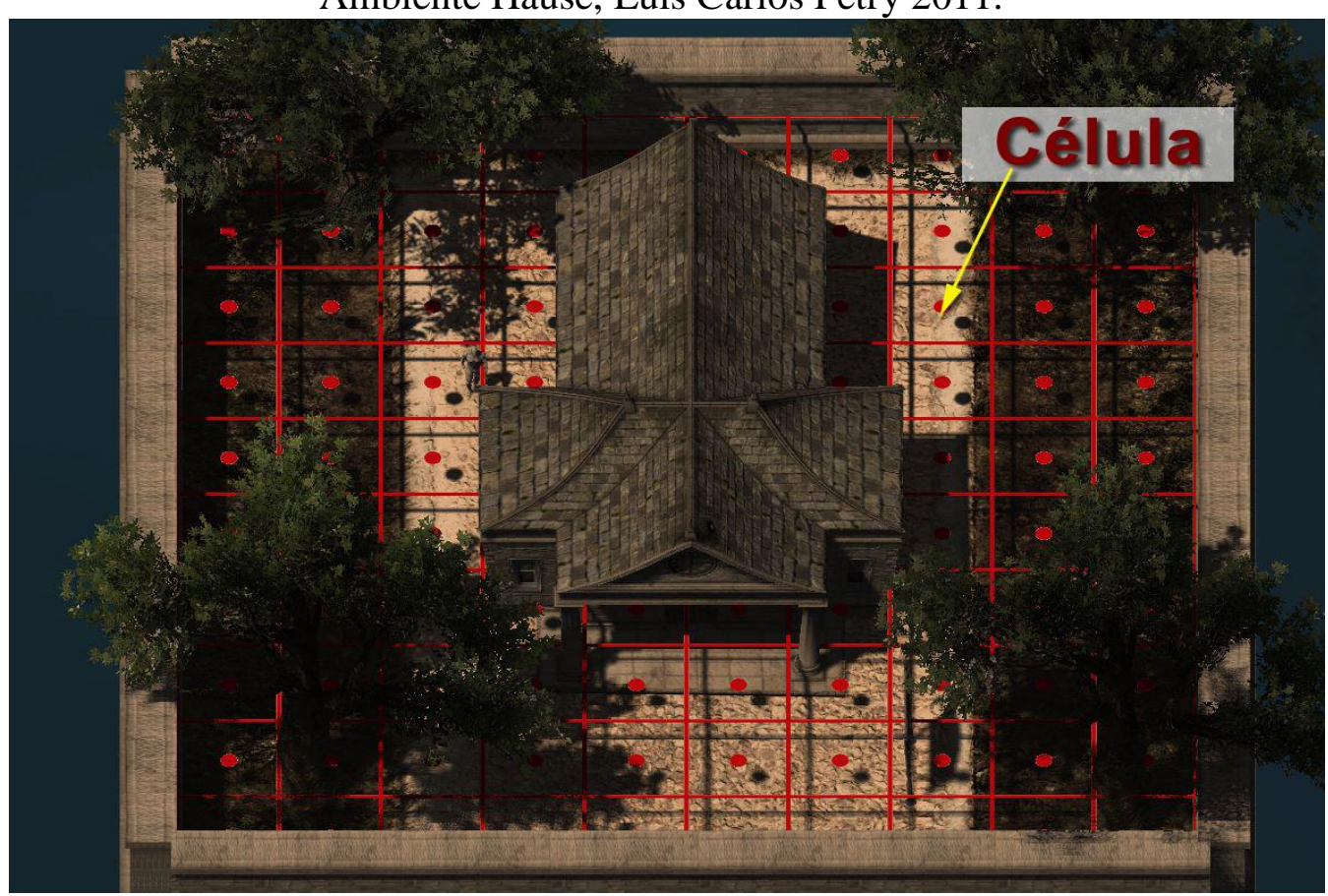

Uma das constatações presentes nos encontros internacionais sobre o tema dos metaversos e games pode ser traduzida na frase que foi utilizada como leitmotif pelo Slactions $2009^{3}$ que diz que o metaverso é emergente. Com esta frase se pretende significar que tanto o metaverso se encontra no rumo dos atuais acontecimentos da civilização, bem como que ele pode ser pensado como o resultado de um longo processo evolutivo, técnico, conceitual,

\footnotetext{
${ }^{3}$ SLACTIONS: Research conference in the Second Life world Life, imagination, and work using metaverse platforms: http://www.slactions.org
} 
cultural e, certamente, econômico. O termo metaverso é introduzido por Stevenson (1992), na novela SciFi, Snow Crash ${ }^{4}$. Ele designa a ação dos sujeitos humanos em ambientes espaciais tridimensionais totalmente imersivos. Neste sentido o metaverso se configura na profusão de espaços digitais nos quais os humanos podem interagir entre si, amparados por um suporte lógico digital que se radica no ciberespaço. Enquanto metáfora do mundo real, o metaverso se coloca como uma possibilidade extensional daquele, sem as suas imposições e limitações físicas (PETRY, 2009, 2010) ${ }^{5}$.

Enquanto conceito amplo, o metaverso é capaz de abrigar uma infinidade de situações digitais. No seu exemplo mais conhecido popularmente, o Second Life, ele pode mimetizar muitas das atividades existentes na vida real e, neste sentido, ele chamou a atenção da cultura de massas e dos movimentos econômicos, com empresas se deslocando para lá e abrindo filiais, com negócios sendo realizados em seu interior, com eventos socioculturais sendo organizados $^{6}$, com encontros individuais agendados ou ocasionais, etc. Em uma acepção pragmática, o conceito de metaverso indica a possibilidade da estruturação de experiências estético digitais omnipresentes. Encontramos nele uma ampliação do conceito de hipermídia de Manovich (2001), o que significa que o metaverso pode ser pensado como a colocação em obra do conceito wagneriano de Ópera total, com a diferença de que seus personagens se identificam com seu público. Ora, neste ponto da identificação entre personagens e público é que encontramos a sua interface com os games e a sua perspectiva ontológica. Os jogos digitais, também chamados de games possuem muitas características em comum com os metaversos $^{7}$. Por exemplo: ambos são construções digitais, ambos permitem a vivência de narrativas imersivas que são investidas e estruturadas no ambiente e, por meio de personagens

\footnotetext{
${ }^{4}$ O conceito de metaverso foi introduzido em 1992, por Neal Stephenson, no seu romance de ficção científica Snow Crash, no qual os seres humanos, como avatares, interagem entre si e com os agentes de software, em um espaço tridimensional que se coloca como metáfora do mundo real. Por isso, diz tratar-se de um mundo dentro de outro mundo, um tipo de mundo virtual que tenta replicar a realidade através de dispositivos digitais que desloquem os sentidos de uma pessoa para a realidade virtual. $\mathrm{O}$ termo foi cunhado para descrever uma realidade virtual sucessora da Internet. A palavra metaverso é um neologismo, uma junção metafórica do prefixo "meta" (que significa "além") e "universo".

${ }^{5} \mathrm{O}$ primeiro e mais famoso experimento deste tipo é o Second Life (http://secondlife.com/ ). Entretanto ele não é o único. Temos ainda projetos de metaversos Open Source, como o Project Wonderland (https://lg3dwonderland.dev.java.net/) e o Croquet Consortium (http://www.opencroquet.org/), iniciativas mais de cunho acadêmico.

${ }^{6} \mathrm{O}$ próprio encontro do Slactions é realizado dentro do Second Life, em um de seus ambientes preparados para conferências e encontros acadêmicos. Mais detalhes disponíveis em: http://www.slactions.org

${ }^{7}$ No presente artigo viso os games tridimensionais, com caracteres digitais e que possuem narrativas de base. São exemplos destes, Myst (1993-2011: http://mystonline.com/es/), Bioshock (2007-2011: http://www.bioshockinfinite.com/) e GTA (1998-2011: http://www.rockstargames.com/gta/), somente para citar três. Na realidade, poderíamos pensar os games massivos e imersivos como um grupo especial de metaversos, ainda que eles guardem características sociais e subjetivas que lhe são próprias.
} 
tridimensionais. Ambos grupos colocam para o usuário a escolha dos rumos de sua navegação, ação e o controle direto sobre a sua personagem actante. Games e metaversos apresentam uma direta evolução do conceito de interface e permite pensarmos os ambientes digitais como um lugar no qual subsistem formas de vida digitais ${ }^{8}$.

O foco de interesse aqui será direcionado a dois produtos da geração dos games imersivos que apresentaram modificações evolutivas interessantes durante a sua saga, ou seja, modificações que os encaminharam no sentido da sua constituição em metaversos-games. São os games Myst (1993-2011) e Bioshock (2007-2013), os quais evoluíram de jogos destinados ao uso individual para ambientes imersivo-massivos, do tipo metaversos completos que permitem aos seus usuários uma imersão em narrativas complexas, bem como a sua exploração espacial dinâmica.

\section{DO UNIVERSO DIGITAL A UMA ONTOLOGIA DOS METAVERSOS E GAMES}

Fig. 3 - De Myst ao Labirinto Artístico-Filosófico 1260. Um caminho do sonho shakespeariano ao conceito.

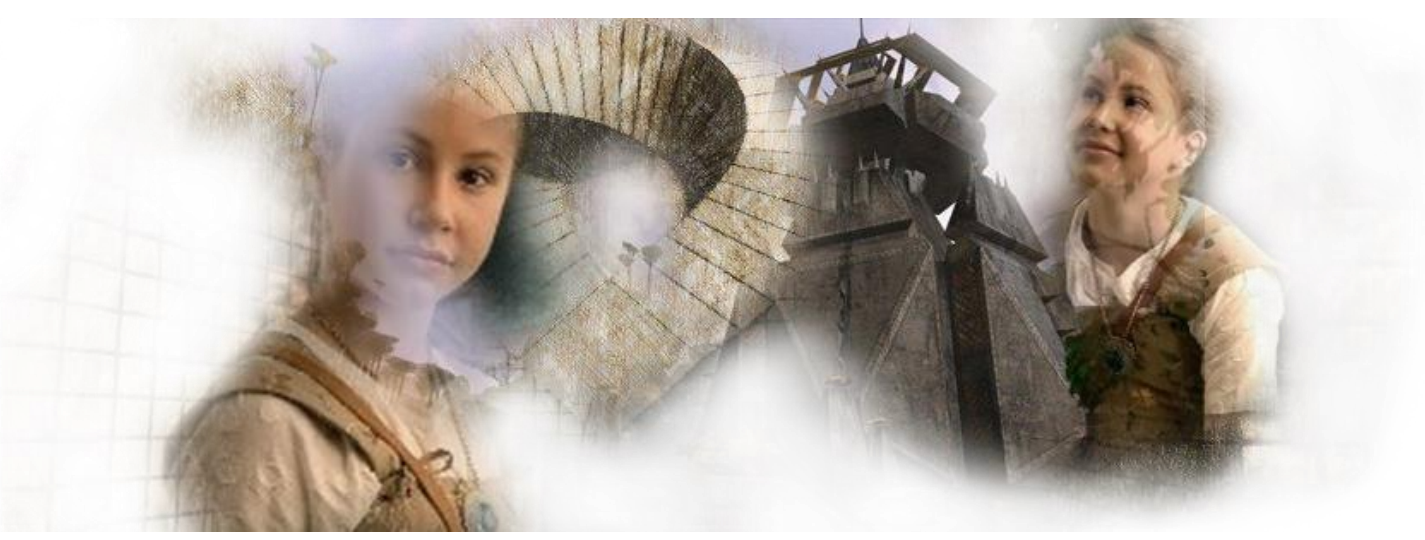

Conceitos como ontologia e universo digital são cada vez mais utilizados por pesquisadores que investigam os domínios do ciberespaço, com seus metaversos e games imersivos. Ambos conceitos se conjugam e se sobrepõem, mesclando-se em uma discussão sobre os fundamentos computacionais e culturais do ciberespaço, suas possibilidades e

${ }^{8}$ Tomando, por exemplo, também no caminho de Manovich (2006), esta ideia se constitui em uma extrapolação da formulação dos jogos de linguagens de Wittgenstein como formas de vida. Nesta direção pode-se consultar o meu artigo, $O$ ciborgue e a arte da hipermídia, publicado nos Anais do $16^{\circ}$ Encontro Nacional da ANPAP (2007), disponível digitalmente em: http://www.topofilosofia.net/textos. 
extensões, enquanto técnica e espaço ${ }^{9}$. Presente em inúmeros autores, o conceito de ontologia é convocado a dar sentido e consistência às mais diversas posições, teorias, situações, e aplicações no campo digital, sendo que o conceito permeia pesquisas que se dedicam sistematicamente a uma reflexão filosófica sobre o digital ${ }^{10}$. Da mesma forma, o conceito aparece nos teóricos que se preocupam com os novos meios ${ }^{11}$, chegando a encontrar um amplo campo de aplicação em pesquisas ligadas à ciência da computação, nas áreas da Web semântica e fundamentos lógicos da computação aplicados a engines de metaversos e games $^{12}$. Em nosso texto Por uma ontologia dos metaversos e games (PETRY, 2011), observamos que, em um sentido estrito o conceito de ontologia precede e dá suporte ao conceito de digital. Este é o motivo pelo qual a questão motiva aos pesquisadores, isto porque ela permite estabelecer uma delimitação, bem como estrutura o panorama de uma aplicabilidade conceitual na classificação ontológica dos universos digitais.

Estudos de autores como Negroponte (1995), Delarbe (2001) e Póvoa (2005), por exemplo, apontam que o universo digital pode ser concebido como o conjunto formado pelos recursos técnicos computacionais, as atividades realizadas por meio destes em ferramentas e ambientes simuladores, bem como seus resultados práticos, os quais resultam em objetos, situações e fenômenos os mais variados ${ }^{13}$. No caso das investigações de nosso grupo de pesquisa, a incidência recai sobre a possibilidade da fundamentação ontológica dos metaversos e games (agora entendidos como delimitações dentro do vasto universo digital), incidindo sobre a questão metodológica da produção de objetos, personagens e ambientes no contexto de narrativas imersivas e interativas. Demandando esclarecimento, esta fundamentação necessita ser desenhada a partir de um conceito prévio de ontologia e, posteriormente, trabalhada a sua aplicação sobre a área de interesse, o campo digital, resultando assim em uma ontologia do digital.

\footnotetext{
${ }^{9}$ Tomo como base aqui a discussão lógica e filosófica sobre o espaço, posto que ele se constitui em uma estrutura ontológica privilegiada (seja ele real ou virtual) na qual o ser e os entes se mostra de inúmeras formas.

${ }^{10}$ Exemplos neste sentido podem ser dados pelos trabalhos de Capurro (1986 e 2008), Heim (1993 e 1997) e Feenberg (2002).

${ }^{11}$ Como nos casos de Turkle (1995), Murray (1997), Manovich (2001) e Hansen (2006).

12 É o caso das pesquisas: Huhns e Singh (1997), Bidarra (2008), Tutenel et alii (2008), Fontes (2009) e Tonéis (2010), somente para citar algumas.

${ }^{13}$ Neste sentido, ver a descrição que realizo desta conceitualização no artigo Por uma ontologia dos metaversos e games (2011), Revista Comunicação e Linguagens, número 42, do CECL, Lisboa, Organização Pedro Andrade (no Prelo). Nele apresento uma reflexão acerca da necessidade de uma apresentação de um conceito de ontologia e a descrição de sua pertinência para o universo digital, isto na medida em que ele pode ser replicado aos seus subdomínios, pensando aqui nos metaversos e games. Ora, a partir de uma delimitação ontológica do universo digital é possível expor-se alguns aspectos que permitem ser relacionados com pontos de vista de teóricos que pesquisam o digital, enfocando a sua recepção da questão ontológica, visando aspectos que contribuem para um entendimento dos processos de criação e trabalho em objetos, ambientes e personagens digitais, por exemplo.
} 
Ora, o conceito de ontologia ${ }^{14}$, deriva de uma longa e exaustiva discussão dentro da tradição das ideias no Ocidente, o qual inicia no momento em que Aristóteles tratou de uma filosofia primeira, incluindo nela, tanto o estudo do ente enquanto ente, bem como o de um ente principal ao qual se subordinavam os demais entes. Dizemos então que a ontologia, do ponto de vista lato, consiste no estudo das propriedades gerais do ser, da existência ou realidade ${ }^{15}$. Será do lado da existência ou realidade que o problema dos entes se coloca para nós sob uma perspectiva ontológica, especialmente quando este ente é o homem e, da mesma forma quando as suas representações alcançam o meio digital. Ora, quando o ente é capaz de pensar-se a si mesmo (“nóesis noéseos nóesis”, é dito por Aristóteles (Met. XI, 9, 1074 b 34) é aberta a porta para a propormos a independência dos signos em um sistema de elementos e posições, ao mesmo tempo articuláveis, relacionáveis e capazes de comunicação (CAPURRO, 2009).

O primeiro elemento que deve ser seguido na busca de um conceito de ontologia digital, diz respeito ao fenômeno e processo da digitalização (CAPURRO, 2009) ${ }^{16}$. Na pósmodernidade a noção de código que se constitui na via regia para nosso acesso ontológico ao universo digital. Todo e qualquer elemento do mundo é capaz de sofrer alguma digitalização, ou seja, ser codificado: de um desenho ao genoma, o corpus da racionalidade digitaliza o mundo na perspectiva de uma totalização. Isto significa que o mundo pode ser pensado como

\footnotetext{
${ }^{14}$ É no início do século XVII que o termo técnico ontologia recebe sua definição. Utilizado por autores como Rudolf Goclenius (1636), por exemplo, ele finalmente foi fixado tecnicamente por Christian Wolff (1679-1754) e Alexander Gottlieb Baumgarten (1714-1762). Em sua obra Philosophia Prima Sive Ontologia (1780), Wolf afirmou que o método da ontologia seria o dedutivo, sendo que o princípio a ser aplicado a tudo o que é, seria o do não contradição. Para Wolf derivava-se aqui o princípio da razão suficiente, o qual diz: nihil est sine ratione, qual tinha como derivado a afirmação da existência e manifestação do ser, sendo o universo uma coleção de seres, cada qual possuindo uma essência que permitiria ao intelecto apreendê-los como ideias claras e distintas. O princípio da razão suficiente foi invocado para explicar por que algumas essências foram concedidas como dotadas de existência, enquanto outras não. De acordo com esta ideia, as verdades sobre os seres são todas necessárias. Assim, a ontologia nada teria a ver com a ordem contingente do mundo, mas somente com a necessária.

${ }^{15} \mathrm{O}$ conceito de ontologia recebe na história inúmeras formulações, nem sempre compatíveis. Uma das acepções consiste em pensarmos a ontologia como a ciência do ser em si, do ser último ou irredutível ou, ainda de um ente a partir do qual todos os demais entes dependem, o que culmina em uma genuína metafísica no sentido da crítica heideggeriana. Outra formulação do conceito poderia ser aquela que nos diz que a ontologia pensa a determinação daquilo em os entes consistem e ainda aquilo em que consiste o ser em si. Nesta última formulação temos uma ciência das essências que resulta em uma teoria dos objetos.

${ }^{16}$ Capurro observa que na pós-modernidade será a noção de código a via régia do nosso aporte para a constituição do projeto ontológico digital. Na modernidade a diferença entre indicação e signo desaparecem, sendo transformadas em relações formais, desvinculadas de seus fundamentos pragmáticos e mundanos. Seu resultado pode ser encontrado nos processos digitais, dentro dos quais os signos $0 / 1$, em um contexto computacional são transmitidos pelas correntes elétricas e pela infovia. Rafael Capurro é filósofo e pesquisador do digital. Residindo na Alemanha, foi docente no Instituto de Filosofia da Universidade de Stuttgart Alemanha (1989-2004). Atualmente encontra-se como Distinguished Researcher in Information Ethics, School of Information Studies, University of Wisconsin-Milwaukee, USA (2009-2012). Site de pesquisa e textos: <http://www.capurro.de/>. Acesso em 10/10/2010.
} 
uma estrutura complexa, a saber, um sistema de relações reticulado e acentrado, ao modo da interpretação de Heim (1997) do ciberespaço, quando chega a relacioná-lo com a ontologia das mônadas de Leibniz (1646-1716) ${ }^{17}$. Jogamos aqui com o fenômeno e processo da digitalização. O transmitido necessita ser digitalizado para poder transitar na rede. Ora, em uma perspectiva projetiva, todos os fenômenos da cultura são capazes de serem transpostos (MURRAY, 1997 e MANOVICH, 2001) ou reduzidos (RUSSELL, 1908) a uma estrutura da lógica binária, dentro da qual podem ser organizados como elementos discretos, quantitativos, qualitativos, inclusive os relacionados com a linguagem natural e os comportamentos (MONTAGUE, 1974 e FONTES, 2009), recuperados e classificados.

Uma segunda formalização conceitual nos fala da sobredeterminação do pensar e sua relação com o fenômeno da digitalização. Ela nos é oferecida pelo conceito heideggeriano de instrumento (Zeug, que também guarda os sentidos de utensílio ou ferramenta), o qual deve participar de uma reflexão ontológica dos metaversos e games. Toda ferramenta ou instrumento, inclusive as digitais, possuem o seu modo próprio de uso e, dentro e a partir dele, abre um conjunto de possibilidades de sentido. A fenomenologia nos mostra que é a partir da flexão do instrumento em instrumentalidade, enquanto seu caráter existencial, que é possível situar-se a posição e a relação do sujeito no digital. Ou seja, para com seus semelhantes, para com os objetos, para com as entidades sintéticas com os quais interage e, finalmente, para com o mundo digital em geral ${ }^{18}$.

Será a partir da ideia de utensilidade, que o mundo digital se coloca e se mostra, mais uma vez, como uma estrutura complexa de relações que são passíveis de serem pensadas do ponto de vista ontológico e, derivadas em uma ontosemântica ${ }^{19}$ instrumental.

\footnotetext{
${ }^{17}$ A proposta de Heim (1997) de uma ontologia do ciberespaço realiza uma conjugação dos pensamentos procedentes da fenomenologia hermenêutica (Heidegger e Marcuse) com a teoria da comunicação (McLuhan). ${ }^{18}$ No sentido pragmático de Zeughaftigkeit, que traduzimos como a utensilidade de algo, a saber, o caráter de ser útil de algo enquanto instrumento, utensílio ou ferramenta, no qual se encontra a chave para compreendermos o funcionamento do digital em suas estruturas modulares e relacionais. É em Ser e tempo (1927) que Heidegger nos apresenta esta dimensão dentro do caráter do ser-no-mundo, situação à qual está submetido o homem enquanto Dasein. Para este ente, o Dasein, é que se abre de forma continuada o mundo em uma condição pragmática na qual seu ser é sempre um ser para e um ser em.

${ }^{19}$ Conforme entendemos os esforços relacionados com os trabalhos de Tutenel, T., Bidarra, R. Smelik, R. \& Kraker, K.J. (2008), isto quando nos apresentam a ideia de que um mundo com objetos ontosemanticamente pensados e programados podem proporcionar sistemas de inteligência artificial altamente produtivos. As ontologias derivadas tem por finalidade facilitar a comunicação entre agentes a partir de diferentes domínios do conhecimento. Neste caso é fundamental uma ontologia dos objetos. Eles discutem o exemplo da Cozinha da Morte (Lugrin e Cavazza, 2006), no qual se apresenta um método de apoio à simulação IA sitado em comportamentos de objetos. O protótipo da Cozinha da Morte, na qual ela (representada por seus objetos) busca infligir o máximo dano no jogador, apresenta um mundo simulado, extremamente perigo. Os objetos da cozinha são classificados ontologicamente. Uma razão funcional é utilizada para produzir situações potencialmente perigosas para o jogador ("player" e seu avatar). Temos objetos e subobjetos estruturados hierarquicamente e
} 
Assim, este binômio compreendendo os elementos da digitalização e da instrumentalidade nos indicam o fenômeno histórico que a fenomenologia identificou como a consumação da metafísica. Esta última postula que o ente em sua totalidade previsível se coloca, de antemão, prefigurado no cálculo de suas possibilidades factíveis (e estocásticas, as quais são uma das formas inteligíveis da cibernética). Em uma palavra: o ente em sua totalidade previsível como consumação da metafísica manifesta-se no produto acabado que temos hoje na rede digital global. Será nesta rede digital, a qual é identificada com a Web, mas igualmente com os metaversos e games on-line, que nos deparamos com o Dasein ${ }^{20}$ como a personagem do argonauta intrépido. É então que encontramos mais uma delineação ontológica, isto na medida em que ela se constitui em uma interpretação possível do ser dos entes vista desde a sua digitalidade (CAPURRO, 2009:02)21. Uma ontologia digital apresentaria então uma possível compreensão do ser a partir do conhecimento humano finito (temporal). Certamente que podemos modelar e programar possibilidades para um metaverso ou games, entretanto, nossa ação inteligível sempre terá, em seu horizonte, um limite que configura a sua própria plausibilidade.

A partir dessa configuração, todas as regiões ou esferas dos entes podem ser concebidas como digitais. Como já observado (MURRAY, 1997), todo o conjunto da cultura histórica sofre atualmente o processo da transposição para o digital. Nesse sentido, o digital se nos mostra como o contexto de uma potência restrita temporalmente e atualizável ${ }^{22}$. Em

todos são dotados de tags que fornecem suas informações (o quê) e funcionalidades (para que). Tal procedimento, ainda que muito simplificado, proporciona um ambiente inteligente, o qual, segundo os autores, poderá ter importantes consequências nos estudos para IA em metaversos e games, isto porque todas as manipulações e interações (baseadas na utensilidade dos objetos) do usuário produzem consequências que podem ser identificadas, classificadas, armazenadas e estruturadas em uma série histórica. Ainda que alguém possa objetar que tais experimentos com metaversos e games sejam por demais primários, podemos ponderar o seguinte: (A) eles se constituem em estudos necessários para um desenvolvimento futuro mais aprimorado; (B) a entrada na computação orientada para o desenvolvimento de IA para metaversos e games realmente se constitui em um marco que produzirá profundos benefícios no que tange aos conceitos de sujeito, mundo e objeto no campo do universo digital. Um de seus efeitos imediatos que pode ser citado aqui, encontra-se no desenvolvimento de emoções em personagens no game para PS3 Heavy-Rain.

${ }^{20}$ Dasein: conceito heideggeriano firmado em Ser e tempo (1927) e que foi às vezes traduzido na língua portuguesa por ser-aí ou estar-aí. O Dasein é um construto e, como tal, resiste à tradução. Capurro coloca um questionamento acerca deste ser dos entes que é o Dasein, situando-o como uma questão e jamais como uma resposta definitiva. Perguntar-se pelo Dasein hoje, incide em uma pergunta a partir de um conhecimento finito (sem que se caia em uma perspectiva essencialista), dentro do contexto de uma cultura digital.

${ }^{21}$ Capurro nos apresenta um aspecto crítico quando nos diz que utiliza a fórmula esse est computari para caracterizar a interpretação digital do ser atualmente dominante. Sua perspectiva apresenta um ponto de vista muito interessante e nos indica que não se trata de que estaria propondo que tudo o que pode ser pensado seja puramente virtual ou que existam as coisas devam ser pensadas essencialmente em bits. A formulação de Capurro pretende dizer o seguinte: acreditamos hoje haver compreendido algo em seu ser quando o analisamos são somente na base da sua possibilidade de ser quantificado como o concebe a ciência moderna, mas também contanto que tal quantificação se baseie no meio digital (Capurro, 2009:2).

${ }^{22}$ Isso fica mais claro quando temos em mente que o contexto digital é, por sua natureza, um contexto finito, 
suma, a potência do digital, destarte as belezas artísticas e científicas realizadas com e dentro dele, é o domínio de uma limitação e restrição associados a um âmbito enunciativo. A cada nova versão dos engines e dos processadores, novos campos de possibilidades são aderidos aos anteriores, enquanto que recursos e formas de linguagens são dadas como obsoletas, caindo no desuso. A cada novo avanço, questões são imediatamente colocadas no que tange aos seus limites expressivos ${ }^{23}$. Cabe a nós discutir agora a questão ontometodológica da produção artístico digital que esta na base dos games e metaversos.

\section{A ESTRUTURA ONTOLÓGICA DO CONTEXTO DE PRODUÇÃO ARTÍSTICO DIGITAL}

Fig. 4 - Horizontes do fazer digital na produção artística em games

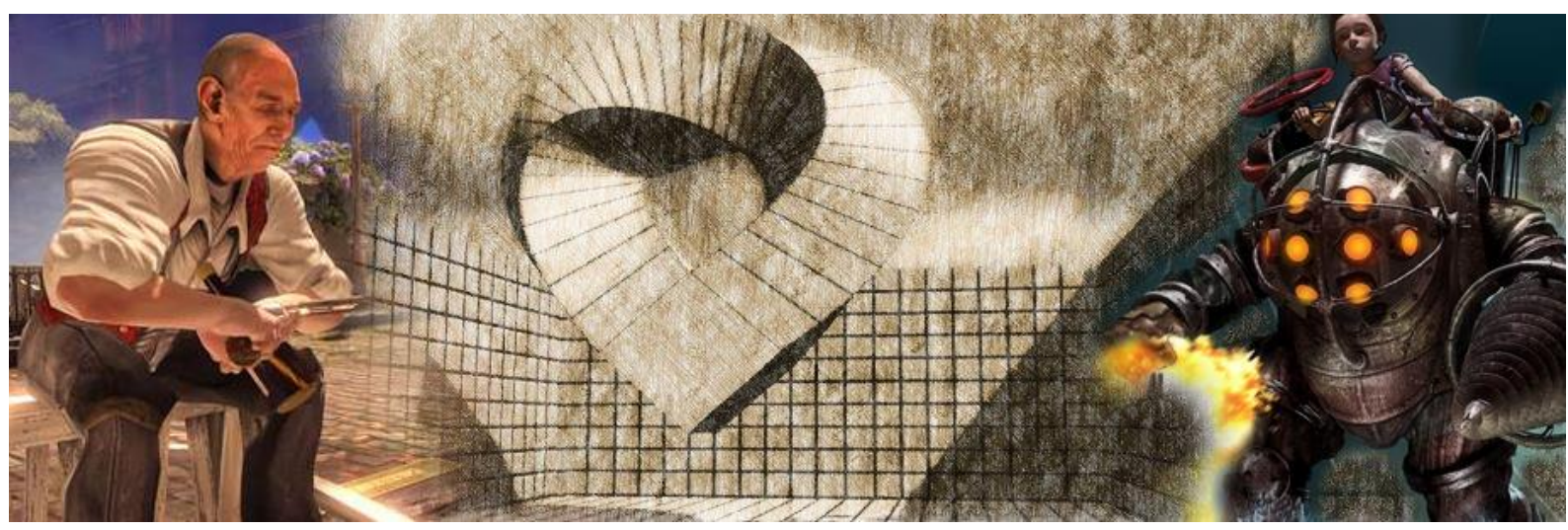

A produção artístico-digital para games e metaversos, regulada por pressupostos ontológicos, se reveste como um elemento da máxima importância em nossa perspectiva. Ela se fundamenta nos elementos ontológicos descritos e os incorpora em seu fazer de forma que podemos perceber a sua fundação construtiva quando trabalha com a produção de ambientes digitais e seus habitantes, tomando-os então como componentes de um universo em seu

inclusivo, nos colocando os limites de uma restrição.

${ }^{23} \mathrm{Um}$ exemplo que pode ser dado neste sentido ocorre no processo de upgrade dos engines de produção de simulações, games e metaversos. Por exemplo, na passagem da versão do Unity 2.61 para a sua versão 3.0, alguns objetos da linguagem foram declarados como obsoletos e substituídos por outros. A versão 3.0 trouxe inúmeros incrementos no sentido de potencializar as capacidades gráficas para a produção de ambientes imersivos e navegáveis. Ela permite produções com um fotorrealismo maior do que a anterior, mas isso a um preço: precisamos de máquinas com capacidade maior de processamento para produzir e, para executar tais ambientes. A evolução, evidentemente, produz também restrições. Ao mesmo tempo que é lançada oficialmente a versão 3.0, discute-se na comunidade de usuários e produtores a lista de recursos que devem ser alcançados com o próximo upgrade. 
conjunto. A ideia de se considerar a produção de um metaverso ou game a partir da perspectiva de um universo em seu conjunto, o qual se relaciona com o conceito pragmático de Worldbuilding, indica que também no campo digital tratamos com a ideia de uma physis, agora revelada como uma physis digital. Será no interior do trabalho com uma physis digital que podemos encontrar os caracteres digitais $^{24}$ como seus residentes. Tais atividades do fazer artístico digital, tal como ocorre com as pesquisas que investem nas perspectivas ontosemânticas da programação de ambientes, deve ser considerada a partir de um ponto de vista ontológico (PETRY, 2003 e SCHAAP \& BIDARRA, 2008).

$\mathrm{Na}$ atividade de construção de mundos e sujeitos digitais, orientada para ambientes tridimensionais interativos que são gerenciados pelos engines de games e metaversos, encontramos o caráter ontológico do trabalho artístico da modelagem tridimensional (MUSARRA, 2011). Enquanto atividade de alto nível reflexivo pragmático, o ato de modelar um objeto digital equivaleria ontologicamente ao ato de pensar a coisa enquanto tal, isto em sua constituição de coisa digital, o que vale dizer, em uma linguagem fillosófica, que consistiria em pensar a coisa, no próprio processo de desenvolvimento coisico. Tal possibilidade e atividade foi designada por nós com o termo topofilosofia (PETRY, 2003) ${ }^{25}$. Ela designa a ação reflexivo pragmática do artista digital e possui uma forte relação com os conceitos de construir, habitar e morar, situados aqui a partir da perspectiva do trabalho sobre corpos plásticos, figurada no pensamento fenomenológico da imagem e da formação de mundo ${ }^{26}$.

Seu ponto de partida é dado pelo conceito gadameriano de experiência estética (enquanto Erfahrung), uma experiência transformadora no pleno sentido do termo, tanto para

\footnotetext{
${ }^{24} \mathrm{O}$ termo charactere deriva da Poética de Aristóteles, designando a representação de uma personagem em uma narrativa. Ele foi tomado pela comunidade técnica de modelagem tridimensional para designar a estrutura tridimensional (meshe) de uma determinada personagem, humano, planta, animal ou alien. Utilizamos o termo caractere ao invés de personagem em função da estrutura artístico ontológica presente em seu processo de desenvolvimento. Neste sentido, ver o nosso texto com Fábio Musarra, O conceito de caractere tridimensional na formação das personagens nos games e metaversos, que se encontra nos presentes Anais do GamePad 2011.

${ }^{25}$ Trabalhamos este conceito em nossa Tese de Doutorado, em 2003, Topofilosofia: o pensamento tridimensional na hipermídia. O conceito foi estabelecido com base em uma reflexão que relacionou áreas como, a fenomenologia hermenêutica de Heidegger e Gadamer, a psicanálise topológica de Lacan, uma discussão de aspectos da lógica simbólica de Leibniz, Frege, Russel e Gödel, resultando em processos metodológico reflexivos sobre a modelagem das estruturas tridimensionais no grande campo da hipermídia, tais como metaversos e games. Ela nos indicou que uma reflexão metodológica sobre o tema da modelagem tridimensional se faz necessária para uma maior compreensão dos fenômenos digitais atuais que constituem o digital, tais como games e metaversos.

${ }^{26}$ Aqui, o corpo plástico afirmado por Heidegger, no texto A época da imagem do mundo se estrutura em uma transformação da técnica que nos leva a postular o seu corpo cibernético, o seu eu-ciborgue. Assim esse euciborgue é, certamente, um eu-híbrido, uma espécie de "entre" um antes e um talvez depois ou, como poderíamos talvez dizer com Nietzsche agora: entre o homem e o além-do homem.
} 
o autor-artista-programador, bem como para o usuário colaborativo e navegador dos ambientes digitais ${ }^{27}$. Será por tal via sinteticamente delineada aqui que a topofilosofia pensa o processo criativo-reflexivo-prático que está na base da modelagem artística de mundos, objetos e sujeitos digitais. Ela se organiza a partir de uma fundamentação, sendo tomada como conceito chave para o entendimento dos processos digitais que realizam a ponte entre os processos artísticos e os computacionais (PETRY, 2006). O seu acento deve ser colocado na interrogação acerca dos domínios plásticos do espaço artístico e a possibilidade da intervenção lógico-matemática participar na reconfiguração da experiência artística ${ }^{28}$.

Desse modo, a modelagem de expressões emocionais e suas condições subjetivas no interior dos games se coloca como uma tarefa no horizonte do trabalho do artista que molda os mundos digitais. Ora, a problematização do corpo plástico na modelagem tridimensional se afirma como um dos aspectos da pergunta ontológica acerca dos games e metaversos: sobre a sua essência e seu ser em si. Ela então é direcionada para a estrutura e contexto dos ambientes digitais, os quais delimitam a situação e existência das novas modalidades de ser do Dasein: elas encontram ali a sua realidade nos avatares e caracteres desses universos digitais ${ }^{29}$. Elas são dispostas no universo que é o game, por exemplo, dentro de um fundamento construtivo o construir/modelar -, e se organizam localmente por meio de funções existenciais habitar/navegar, ao modo de cyber entities ${ }^{30}$, utilizando uma expressão de Heim (1993).

\footnotetext{
${ }^{27} \mathrm{O}$ conceito de experiência estética colocado por Gadamer (1960) nos conduz até a reflexão acerca do construir, habitar e pensar (Heidegger, 1994), o qual fornece a circunscrição ontológica possível para a ideia da modelagem de objetos e ambientes dentro de um dado ambiente digital. Tal como no alemão bauen, construir sua morada, equivale ao amalgamar em tintas uma pintura e, igualmente a transformação de um objeto (digital), conferindo-lhe uma determinação subjetiva para além do caráter de simples coisa.

${ }^{28}$ Mais especificamente, com Gadamer (1960), chegamos à conclusão que seria do lado da arte que poderíamos encontrar e situar a verdade, ao passo que do lado da ciência normal somente contaríamos com o método, a sistematização do projeto preconcebido de mundo. Dessa forma, a apropriação do espaço na espacialização do fazer artístico conduz o homem ao habitar, dentro do qual espacializar é situar as coisas, ou seja, colocar-se junto delas e ali tornar a compreensão operativa, mas não maquínica (STEIN, 2009). Esse seria o espaço de trânsito de uma possível reflexão topofilosófica, em seu devido rigor.

${ }^{29} \mathrm{~A}$ estrutura do caractere digital abriga uma composição híbrida entre o corpus humano e o corpus da técnica. Significa que estamos lidando com uma figura híbrida que, como habitante ao mesmo tempo de dois mundos, ou que é construído na junção de sujeitos situados em dois mundos ao mesmo tempo, não pode pertencer exclusivamente a nenhum deles. A nosso ver, a questão ainda não está fixada e demandaria mais trabalho reflexivo.

${ }^{30}$ Identificamos aqui um duplo aspecto que é revelador de uma limitação. As ciber entidades, ainda que dotadas de comportamentos ontológicos, não deixam de situar-se no campo restrito da imagem computacional, mesmo quando disponibilizadas através do engines imersivos e em tempo real. Elas não possuem a mesma co-existência, co-plasticidade e co-materialidade dos corpos do mundo real, encontrando-se, em função dos limites computacionais atuais, mais próximas das estruturas ontológicas da pintura. Ora, em A im@ gem pensa: aspectos quânticos da imagem cibernética (2008), me dediquei a exposição de um projeto sistemático que discutiu os fundamentos ontológicos da imagem no ciberespaço. Naquela oportunidade apresentei a possibilidade de compreendermos a imagem de síntese, a imagem digital, ou seja, a imagem digital produzida por e com recursos computacionais $\mathrm{Bi}$ e Tri dimensionais, como um objeto cognitivo e, assim, dotado de força e estrutura ontológica. É neste caminho que somos sempre levados a pensar as estruturas ontológico-cognitivas do universo
} 
Ora, tal processo se produz, não mais como uma urbanização do pensamento como postulava Vattimo $(1985)^{31}$, mas sim, agora, em uma nova época, como uma digitalização do pensamento, fazendo que com que se mostre que no digital as questões ontológicas se fazem presentes, desvelando assim, novos horizontes em função da genuína propriedade deste novo habitar do pensar do Dasein.

Chegamos ao ponto de poder organizar as associações ontológicas que aqui nos nortearam no digital e aplicá-las ao contexto dos games e metaversos. Observamos que todos os objetos tridimensionais que estão presentes nos games e metaversos indicam estruturas plásticas que demandam o trabalho construtivo que se destina a uma presença ou a formação de uma habitação no digital. Ora, a perspectiva aqui seguida indica que todo conceito se expressa no digital através de uma narrativa. No interior desta última é que os objetos e sujeitos possuem vez e voz, a saber, seu lugar enunciativo. Toda imagem é plena de significado, isto na medida que é a própria imagem que serve de textura vívida para a carne plástica dos sujeitos digitais, dos objetos, da arquitetura e, inclusive das cores dos céus dos mundos digitais. Elas necessitam ser pensadas como texturas e jamais como meras ilustrações. Em uma palavra: elas são texturas conceituais (BAIRON \& PETRY, 2000). Como tais, as imagens constroem a superfície da estrutura dos corpos plásticos que dá forma e volume aos objetos.

Da mesma forma, toda estrutura da paisagem sonora que preenche com sentimentos e tonalidades o universo dos games denuncia o trabalho extenuado de construção de uma presença viva que se coloca junto ao Dasein digital enquanto texturas sonoras (BAIRON, 2005).

Finalmente, todo o código invisível, o conjunto de proposições lógicas que regula a máquina de estados que vive no coração dos games e metaversos, fornecendo a cola flexível para a existência em ato, indica a ação do movimento que liga entre si as coisas do mundo. É ele que fornece a estrutura possível da enunciação, bem como o norte ético e estético que irá definir os seus níveis de restrição ou liberdade.

Objeto, textura, paisagem sonora e código são elementos fundantes da constituição do

digital no qual subsistem os metaversos como moradas possíveis de um Dasein digital. Mesmo em função da presente limitação exposta, estas ciber entidades, os chamados caracteres (às vezes na posição de ciborgues), eXistem (no sentido lacaniano do termo).

${ }^{31} \mathrm{O}$ contexto de uma urbanização do pensamento é coloca por Vattimo (1985), a partir de uma expressão de Habermas, em relação a interpretação do pensamento de Heidegger realizada por Gadamer. A urbanização do pensamento de Heidegger por parte de Gadamer teve como consequência uma maior aproximação daquele com pensamentos de outros filósofos, tais como Wittgenstein, sem cair em estratégias reducionistas. A urbanização é, enfim, uma reflexão e interpretação que aproxima questões de fundamento. 
conceito de espaço digital que subsiste nos games e metaversos. Modelamos um corpo para que subsista em um dado espaço que pode vir a se constitui em um espaço de morada digital. Considerando tais elementos nos perguntamos aqui sobre a estrutura ontológica do espaço no interior de nossos dois games-metaversos que consideramos modelares, a saber, Myst $e$ Bioshock, realizando, por enquanto, ainda uma abordagem exploratória ${ }^{32}$.

\section{ASPECTOS DOS MUNDOS E NARRATIVAS DE MYST E BIOSHOCK}

Fig. 5 - Fusão de horizontes nos games.

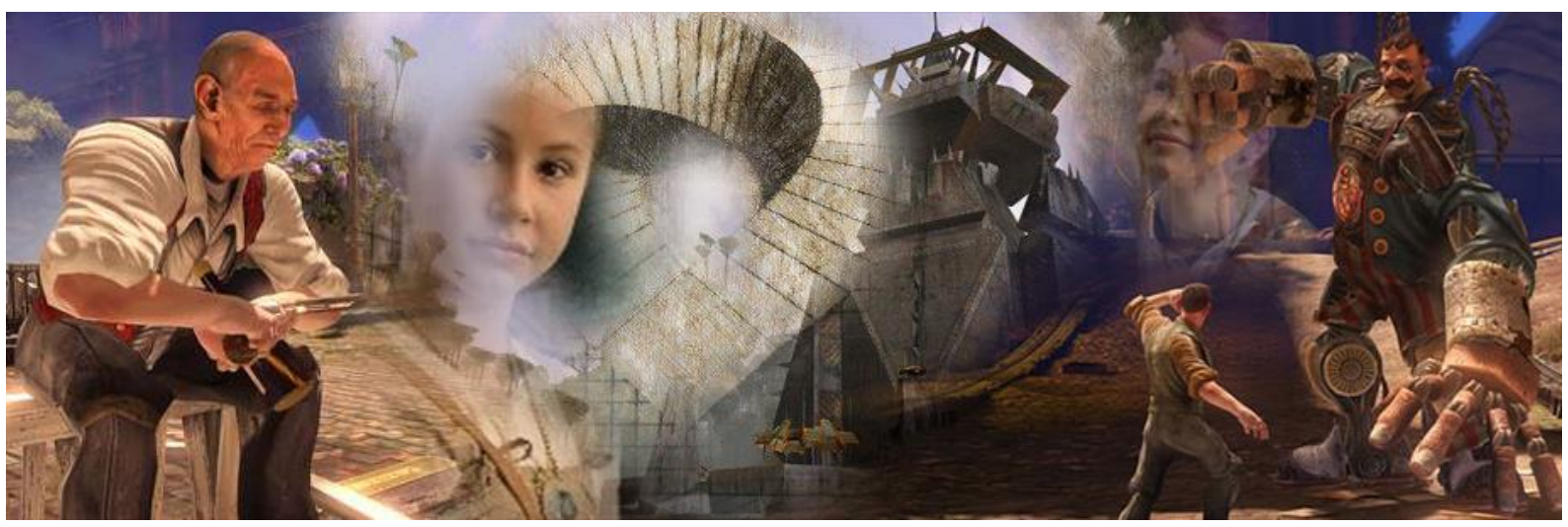

$M y s t^{33}$ é o nome de uma ilha misteriosa em algum lugar da imaginação digital. Seu

\footnotetext{
${ }^{32} \mathrm{Em}$ nossa pesquisa, inicialmente classificamos as características e propriedades que podem ser descobertas e organizadas em Myst e Bioshock, de acordo com dois grandes grupos, até certo ponto, óbvios: existem aquelas características ou propriedades que lhe são comuns, enquanto que podem ser encontradas outras que são próprias a cada um deles. Observamos que estes dois games organizam dois sistemas de mundos altamente complexos, cada qual com suas leis fundamentais, sistemas de relações, etc., mas que, entretanto, possuem aspectos que são comuns. No presente artigo nos dedicaremos às características que compõem na categoria ontológica do espaço, a qual deriva em uma navegação e uma exploração do mesmo.

${ }^{33}$ Myst conta com cinco episódios fundamentais: Myst I (1993), Myst II Riven (1998), Myst III Exile (2001), Myst IV Revelation (2004) e Myst V End of Ages (2005). Esta sequência forma a estrutura fundamental do universo de Myst. Após isso temos três edições que dão continuidade a história, mas em outro contexto: URU Ages Beyond Myst (2003), URU to D'ni (2004) apresentada como a primeira expansão para a nova série, seguida de URU The Path of the Shell, o qual foi vendido separadamente. Logo depois, a Cyan publica uma nova edição, intitulada URU: complete chronicles, que reunia em dois CD's toda a série das Ages beyond Myst em um sistema integrado. Ainda em 2003, a Cyan já trabalhava no metaverso URU Live. Em fevereiro de 2004, devido a inúmeras dificuldades, principalmente com seu parteiro comercial, a GameTap, o universo foi abandonado. Grupos de fãs mantiveram uma versão não-oficial Online do mesmo até 2007, a qual igualmente foi cancelada por motivos financeiros ligado ao suporte dos provedores. Por volta de 2008, a Cyan conseguiu retomar os seus direitos sobre Myst e reiniciou os trabalhos para colocar de volta na rede o seu metaverso. Em 2010 Myst Online: URU Live ressurge reunindo seus usuários em um metaverso completo, com o detalhe que a linha central da narrativa aberta na série $U R U$ é retomada, mas agora em uma comunidade Online massiva. A base Web de Myst Online é: http://mystonline.com/en/. O fórum oficial é http://mystonline.com/forums/ e o o site da comunidade brasileira, mantido pela pesquisadora livre Lorna Dannan, A grande caverna, é: http://www.grandecaverna.com/. Somos eternamente gratos a Dannan pela sua ajuda e suporte constante em nossa pesquisa sobre Myst.
} 
nome indica imediatamente o núcleo ao redor do qual a trama irá ser desenvolvida em suas várias edições. Em Myst você sempre está às voltas com um mistério fundamental que necessita ser solucionado e, acerca do qual, você nada sabe de antemão. Ainda mais, da solução do mistério depende a sobrevivência do universo digital de Myst. Do ponto de vista da ideia geral do universo do game, o universo de Myst (1993-2011) compreende um número de lugares que são chamados de Eras que estão ligadas umas às outras por portais de passagem que são abertos por intermédio dos livros de ligação (Linking Books). Cada uma das Eras abriga uma série de construções arquitetônicas em um estilo new age que se inspira no art noveau, o que tem como consequência direta que cada construção e, cada ambiente dentro de uma mesma construção, possui um significado particular, indissociavelmente ligado a história de Myst.

Em toda a série, do Myst original até o atual metaverso online, o jogador é convocado a auxiliar na solução dos mistérios que ali se encontram. Inicialmente você tem de solucionar um problema de traição que ocorre no interior da família de Atrus, líder remanescente da civilização $D^{\prime} n i$. Mais adiante, em Riven, na segunda versão do game, você irá descobrir que o grande perigo que ameaça todo o universo reside no embate entre filho e pai, entre Atrus e Ghen, este último, o patriarca supostamente enlouquecido pelo esforço de restauração da tradição $D^{\prime} n i$. De segredo em segredo, de revelação em revelação, o jogador chega até o final da primeira grande série, em End of Ages, descobrindo que as maravilhas da civilização $D^{\prime} n i$ possuem também o seu lado obscuro... Atualmente, em Myst Online, juntamente com outros pesquisadores, o cibernauta agora se defronta com o esforço de auxiliar na recuperação arqueológica dos restos do passado. Equipes organizadas de pesquisa realizam a tarefa em meio a dificuldades ou armadilhas que são apresentadas por uma civilização extinta ou, quem sabe ..., ao menos é o que se supõe. A questão não está definida, entretanto.

Bioshock ${ }^{34}$ apresenta um game no qual, em sua primeira versão, o jogador é colocado na figura do único sobrevivente, de nome Jack, de um desastre aéreo em algum lugar do atlântico. O ambiente do jogo se passa em Rapture, uma cidade submersa que havia sido a sede de notáveis cientistas do mundo que ali haviam se reunido, sob a liderança do cientista e

\footnotetext{
${ }^{34}$ Bioshock é um game produzido pela $2 K$ Games (http://www.bioshockgame.com), com sua primeira versão lançada em 2008. Do ponto de vista artístico o game apresenta uma narrativa interativa ao modo SciFi ambientada em uma estética da última fase do art noveau, a qual, segundo alguns pontos de vista pode ser definida como Steampunk. Suas versões posteriores são: Bioshock 2, Bioshock: Fall of Rapture (em formato multiusuário) e, na fase final de desenvolvimento, Bioshock Infinite. Gostaria de remeter nosso leitor aos artigos publicados na Eurogames que oferecem bons panoramas do game e o analisam em alguns aspectos fundamentais. São eles: Bioshock - Antevisão, por Tiago Lopes: http://www.eurogamer.pt/articles/bioshockantevisao e Bioshock - Análise, por Ricardo Madeira: http://www.eurogamer.pt/articles/bioshock-analise .
} 
milhardário Andrew Ryan, em total liberdade, de censura e controle, para realizarem suas experiências científicas em prol da evolução humana. Aqui começam as complicações. Além dos experimentos cada vez mais terem com o tempo se tornado bizarros e, assim liberando o lado escuro da alma dos cientistas e, principalmente, o de Ryan, a descoberta e utilização das Adam, pequenas células geradas por organismos do fundo do mar, colocam sérios problemas.

Além do mais, a utilização massiva das Adam tem uma direta consequência: elas produzem profundas e permanentes mutações em humanos, tornando-os física e mentalmente mais desenvolvidos (ou aberrantes). Outra consequência é a que os humanos se tornam cada vez mais enlouquecidos, devido ao agravante de que a substância possui um componente viciante. A abstinência torna-se cada vez mais insuportável. Estes fatores produziram uma enorme dependência nos habitantes de Rapture, levando-os a um estado de hostilidade geral, a partir do qual se instala um clima de guerra e, dentro dele um único propósito: conseguir mais uma dose de Adam. A nossa personagem, Jack, tem a infelicidade de cair neste ambiente. Além de descobrir as macabras maravilhas geradas por esse mundo, ao mesmo tempo, selvagem, tecnológico-bizarro e mutante, ele tem de lutar permanente por sua vida. Em meio a seu caminho, a Adam e, muito mais do que lutar pela própria vida, ele encontra surpresas que proporcionam mais conhecimento e, digamos, evolução.

De volta ao contexto de Rapture, em Bioshock 2, a segunda versão do game, o jogador é convidado a repetir a experiência de mundo bizarra, mas agora sob outro ponto de vista, o de uma das personagens centrais contra a qual você teve vários embates na visita anterior: a figura Big Daddy ${ }^{35}$. Se antes, no Bioshock original, o jogador por vezes tinha de enfrentar os Big Daddies, agora ele tem a oportunidade de vivenciar a situação pelo olhar e contexto de um deles. Esses seres poderosos acompanham e protegem as Irmãzinhas, pequenas meninas que se ocupam em retirar a energia e as Adam que ainda podem ser encontradas nos cadáveres dos habitantes de Rapture. Tanto elas como os Daddies se nutrem das mesmas e, de certo modo, para muitos não está claro qual a relação entre tudo isso e a voz over (Ryan) que atormenta Jack. Os Daddies foram criados dentro do Programa Protector, como ideia do Dr. Yi Suchong, um dos notórios cientistas do programa de pesquisa de Rapture. O problema é que muitos dos sujeitos que foram transformados em Daddies não eram psicologicamente

\footnotetext{
${ }^{35}$ Os Big Daddies (originalmente nomeado como Protetores) derivam de seres humanos geneticamente alterados, nos quais seus órgãos são enxertados em um traje de mergulho gigante. Sua finalidade principal consiste na proteção as Irmãzinhas, acompanhando-as no ambiente de Rapture. Luzes coloridas que podem ser vistas em seu capacete indicam o estado emocional do Daddy: verde, indicando que é hipnotizável e amigável, amarelo indicando consciência, mas apresentando indiferença em relação ao meio ambiente e, vermelha, indicando alta hostilidade para com qualquer um que não seja uma Irmãzinha.
} 
estáveis para encarar o desafio de perder permanentemente a sua humanidade em prol de uma meta maior. Se tornam psicoticamente instáveis, o que constrói uma ponte para uma versão multiusiária do game, o Bioshock Fall of Rapture.

Podemos jogar as duas versões do jogo, Bioshock e Bioshock 2, sem que venhamos a nos preocupar com a complexidade de seu mundo e dos seres criados pela equipe de desenvolvimento da $2 \mathrm{~K}$ Games. Mas quando nos deslocamos dos interesses de um usuário ocasional, para nos convertermos em um fã, somos levados a descobrir inúmeras facetas do universo de Bioshock. Um dos achados impressionantes é a Wikia que foi criada para Bioshock, dentro da qual temos informações e conhecimento sobre as quatro edições: Bioshock, Bioshock 2, Bioshock Fall of Rapture e Bioshock Infinite ${ }^{36}$.

Seguindo pela saga de Bioshock, temos a sua versão Fall of Rapture, a qual se constitui em um game do tipo multiplayer. Ela foi lançada internacionalmente em 2010 para as principais plataformas e serviu de preparação para a construção do grande Bioshock Infinite, ainda em desenvolvimento. $\mathrm{O}$ cenário deste último se passa em Columbia, uma cidade flutuante no céu. Como maravilha tecnomecânica, Columbia é formada por edifícios e plataformas que foram construídas e acoplados a balões que possuem reatores gigantes, autossustentáveis, que tem a finalidade fazer a cidade flutuar sobre as nuvens. Estima-se que a cidade fora construída pelo governo americano, a tendo concebido como uma espécie de símbolo dos ideais americanos, flutuando sobre os céus em um momento histórico no qual os EUA emergiam como uma potência mundial (finais do século XIX e meados do século XX). Mas, um projeto que se inicia como uma nova esperança, rapidamente sai fora do controle. Os cidadãos de Columbia de debelam mostrando a verdadeira natureza da cidade flutuante: sua natureza separatista e a manifestação de um fenômeno inexplicável... Mistérios novamente a atormentar a mente dos jogadores. Com isso, temos como resultado o desaparecimento de Columbia nas nuvens. Porém, ficamos sabendo que logo após o desaparecimento da cidade sob as nuvens, inicia-se um guerra civil entre os habitantes que mobilizou quatro facções ideológicas. Na realidade as facções lutam entre si pelo controle de uma jovem, Elisabeth, mantida em cativeiro desde a sua infância e que possui habilidades psiônicas extraordinárias. O game situa-se no ano de 1912, e o agente Booker DeWitt é enviado para localizar a cidade e libertar Elizabeth.

Como pode ser observado pelos resumos, ambos os jogos são generosos na densidade de suas estruturas de mundo e narrativas correspondentes. Do ponto de vista do mundo que

\footnotetext{
${ }^{36}$ A Wiki pode ser acessada em: http://bioshock.wikia.com/wiki/BioShock_Wiki (Acesso em 10/05/2011).
} 
eles constroem, sua estrutura de espaço é ontologicamente complexa e de grande riqueza. Sobre a sua relação comparativa é que nos deteremos agora.

\section{MUNDO E ESPAÇO NAVEGÁVEIS NA ABERTURA DE ESTRUTURAS ONTOLÓGICAS}

Fig. 6 - Ontologia plástica do digital

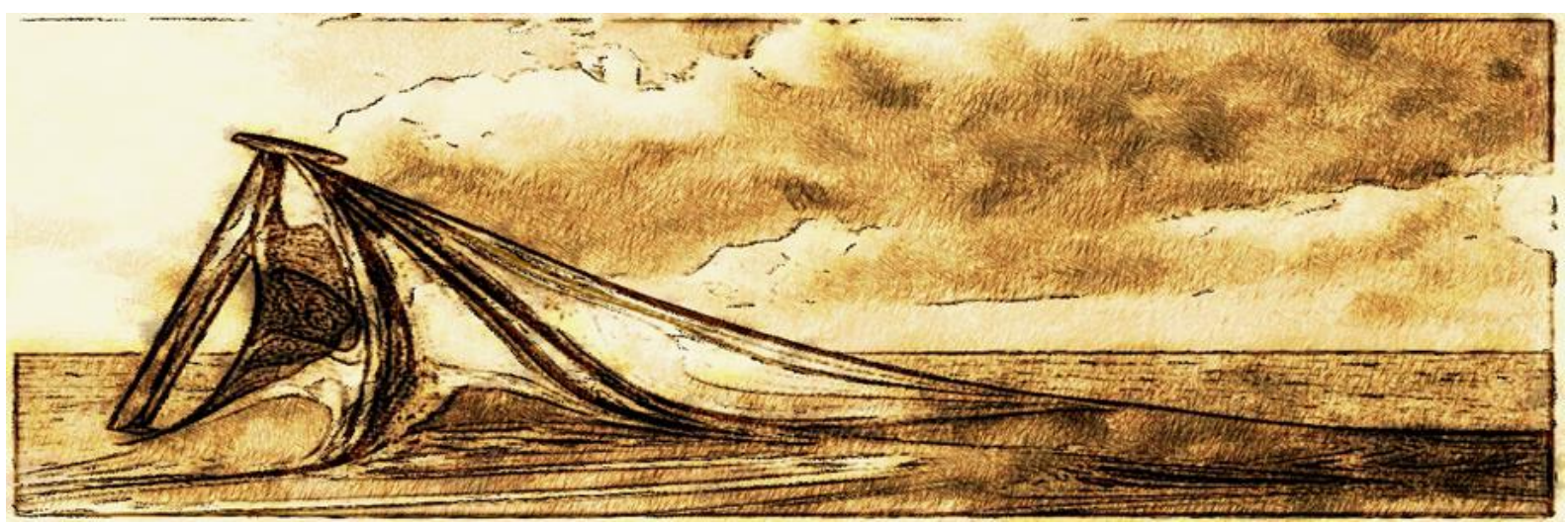

Manovich (2001) é um dos pesquisadores dos novos meios que enfatizou uma das fundamentais qualidades do espaço digital: a de ser potencialmente um espaço navegável. O espaço se constitui, como vimos, em uma estrutura ontológica que abre as portas para que o homem se enlace em uma atividade de exploração que designamos como lógica da descoberta. Tanto Myst como Bioshock se estruturam como espaços navegáveis que propiciam imensos ambientes de exploração para seus visitantes. Particularmente, Myst estrutura-se, desde a sua primeira versão em 1993, como um espaço navegável: o jogador move-se por entre as suas eras pesquisando seus enigmas, resolvendo seus puzzles e descobrindo seus segredos, o que faz com que a narrativa e a ideia de uma cultura $D^{\prime} n i$ prosperem. Este pode ser um dos primeiros elementos ontológicos que estão presentes no game-metaverso, considerando tanto as suas versões monousuário, como a atual versão do metaverso massivo de Myst Online: o game é pautado por um espaço navegável que se abre em uma lógica da descoberta, necessária em sua estrutura. Cada enigma ou puzzle apresentado em Myst contribui para a resolução de uma parte de seu mistério e, permite, que você possa avançar no entendimento do jogo, na compreensão da narrativa e, inclusive, na própria navegação. Nesse processo o sujeito da navegação consome horas diante do jogo e reforça as suas estruturas lógicas elementares, se pensarmos nas ideias de construção do 
conhecimento de Piaget e do estruturalismo (TONÉIS, 2010) ${ }^{37}$. Trata-se aqui de somente um exemplo, dentre muitos.

A estrutura de livre navegação, associada a uma economia de pesquisa que se abre à exploração aberta são outras características derivadas da ontologia do espaço. Tanto em Myst como em Bioshock o jogador é levado a perscrutar os mais recônditos lugares, a examinar cada um dos itens e objetos oferecidos, a espreitar os animais e seres e, como no caso particular de Bioshock, a examinar os seus corpos mortos. Isso somente é possível se podemos contar com uma ampla liberdade de movimentação e interação. Assim, os objetos se tornam elementos de uma economia digital que se apresenta no jogo, necessária para a sobrevivência em um meio hostil (Bioshock) e imprescindível para compreender melhor o mundo no qual se está e, decididamente, progredir nele (Myst e Bioshock $)^{38}$.

Associados a uma navegação e uma lógica da descoberta, somos então confrontados em Myst e em Bioshock com a emergência da alteridade na forma do adversário oculto. Mais do que companheiros da aventura no game, os sujeitos sintéticos que se colocam diante de nós na ação viva da narrativa que progride, tem a tarefa de nos desafiar. Em Myst nosso antagonista é, na maior parte do tempo, suposto, indireto. Mais para o final da aventura topamos com ele, ainda que elementos mais dramáticos e complexos começaram a ser introduzidos, na versão de 2004, em Myst IV Revelation, dentro da qual temos a presença de sujeitos com os quais contracenamos e que, inicialmente, não sabemos se pretendem realmente nos ajudar ou, ao contrário, se estão apenas interessados em nossa ruína. Em Bioshock a figura do antagonista se coloca quase que imediatamente. Somos confrontados pelos cidadãos mutantes de Rapture assim que saímos do elevador. Em Bioshock Infinite (ainda em desenvolvimento), quando escolhemos o item da arma que nos é sugerido em um cartaz, os habitantes de Columbia, se tornam nossos antagonistas imediatamente. Temos a impressão de que se não estamos armados não existimos: somos então fantasmas que perambulamos. Ambos os games se caracterizam por serem pautados por uma estética da exploração e uma economia da exploração do ambiente e seus objetos que circulam ao redor

\footnotetext{
${ }^{37} \mathrm{Um}$ exemplo pode ser dado, encontrado em Myst I: trata-se o puzzle do cofre que guarda uma caixa de fósforos. Com os fósforos podemos acender uma caldeira e fazer funcionar o mecanismo que faz com que uma gigantesca árvore se transforme ou revele um elevador em seu tronco que dá acesso para uma outra Era (mundo mágico). Os números são encontrados em uma parte secreta da Biblioteca de Myst. Assim, dentro da ideia de que existem planos dentro de planos, ou seja, de que um enigma esconde outro em seu interior, os puzzles de Myst, ao mesmo tempo que revelam soluções ao serem solucionados, mostram outros caminhos que podem ser investigados.

${ }^{38}$ Pensamos nós que definir um jogo pautado pela economia da exploração é definir a progressão do conhecimento do homem dentro do ambiente digital.
} 
de uma ética-estética de suas alteridades.

Em ambos, Myst e Bioshock temos a constituição de seus mundos como símbolos centrais do jogo. Neles o conceito de Worldbuilding adquire um sentido ontológico. Neste sentido: o que lhes é comum? Ressalta aos olhos do navegador curioso em Myst e desesperado inicialmente em Bioshock o cuidado com o qual ambas equipes de realizadores trataram a questão do design de seus ambientes. O design de ambiente nesses dois jogos se organiza apresentando uma riqueza de detalhes surpreendente, a partir dos quais, o player $^{39}$ é envolvido em um sentimento e sensação psíquica de imersão (MURRAY, 1997, MANOVICH, 2001) incomparáveis. A imersão prepara o terreno psicológico para que, quando o sujeito da navegação interagir com objetos, eles respondam à sua ação (com o mouse ou controle), lhe conferindo um forte sentido de agência. Esta, por sua vez, tem como resultado direto a transformação do ambiente do game, bem como afeta ao sujeito do jogo (TURKLE, 1995), tanto no que diz respeito à situação de seu player (com sua correspondente câmera e/ou avatar), como o seu usuário, aquele que joga o jogo. Identificamos esse conjunto complexo formado por um design de ambiente que é dado à navegação e que é capaz de produzir profundas alterações no mundo do game e na esfera do seu jogador, dentro de uma acepção corrente na indústria dos games, naquilo que é designado como Worldbuilding ${ }^{40}$.

A observação dos nossos dois exemplos modelares, mostra que ambos se constituem em espaços navegáveis que são possíveis a partir de uma profunda organização do mundo digital e imaginário que os dá suporte. Trata-se aqui da estrutura presente no conceito de Worldbuilding, a qual, a nosso ver, está situada no horizonte da concepção do mundo como símbolo do jogo (FINK, 1960). Será dentro desse horizonte que o construir, enquanto o modelar tridimensional, nos pode conduzir na direção de uma habitação digital na narrativa que ali se desenvolve. Assim, os conceitos e associações ontológicos sugeridos por nós que estruturam o mundo digital, mostram aqui os seus efeitos, propiciando uma navegação que se

\footnotetext{
${ }^{39}$ Utilizamos aqui a expressão inglesa player para indicar aquele que conduz a navegação no mundo tridimensional interativo do game. Trata-se de uma estrutura lógica em algumas engines, como por exemplo o Unity $3 D$, com seus controles, componentes, etc. O player pode ser pensado como a estrutura lógica, comandada pelo sujeito do jogo, o usuário, que controla uma câmera e/ou um avatar no game. Do ponto de vista formal, o player é, sempre o jogador, mas que por jogar o jogo, por ele também é jogado, segunda a acepção de Gadamer (1960).

${ }^{40} \mathrm{~A}$ Worldbuilding é definida como o processo de construção de um mundo imaginário associado a um universo ficcional. Resumidamente podemos dizer que a Worldbuilding compreende o conjunto de leis ou regras físicas, biológicas, evolucionistas, sociais, econômicas, psicológicas, culturais, etc., que entram na composição de um dado universo ficcional. O termo foi popularizado pelas oficinas de escritores de ficção científica na década 1970, ainda que inúmeros autores da história da literatura tenham utilizado este método na construção de suas obras. Um exemplo gaúcho interessante que pode ser dado, associado ao método do Worldbuilding, figura no trabalho que Érico Veríssimo realizava para seus romances, desenhando seus personagens e o mundo no qual eles existiam (Cf. VERÍSSIMO, 1976).
} 
desdobra em exploração e, dispondo a descoberta e o encontro com a alteridade (seja ela nosso semelhante em um sistema multiusuário e/ou sintética, na forma dos NPC's dotados de IA).

Os objetos digitais são o resultante da ação da modelagem tridimensional, a qual repousa sobre o princípio ontológico do construir/modelar. Como barro digital eles adquirem a estrutura de coisa digital ou ente digital na perspectiva de um corpo plástico. Mas, para que eles possam adquirir a consistência pretendida e produzirem a sensação de verossimilhança, necessitam serem revestidos com as texturas que resultam do trabalho da imagem digital. Enquanto textura-imagem, esta se fixa ao objeto como seu fundamento expressivo e corpóreo da ideia fundante do objeto: ela sempre será uma textura conceitual. A imagem é sempre imagem em movimento e, imagem no tempo (DELEUZE, 1983 e 1984). Por isso é que dissemos em outro lugar que a im@gem pensa: ela sempre terá algo a dizer para um sujeito da consideração (PETRY, 2008). Objeto e imagem se co-pertencem em uma temporalidade que se expressa no movimento do mundo digital. Para que eles possam advir ao sujeito em uma forma de diálogo, se faz necessária a coordenação de dois outros elementos já referidos: som e movimento. Enquanto manifestação da vida digital, o som dentro do game/metaverso se nos apresenta como a manifestação dos sentidos possíveis que ali podem existir: alteridade, enunciação, fenômenos expressos na paisagem sonora do mundo digital que, prefigurados na imaginação dos seus realizadores subsistem como forças expressivas de texturas sonoras, organizadas pelo movimento líquido que o código propicia, o movimento invisível de cogitação de possibilidade e projeção de capacidades que são imajadas para o sujeito da navegação. Em uma palavra: programar para games e metaversos significa dispor a possibilidade e a potência entre as várias instâncias do mundo. Significa propor capacidades enunciativas.

Pensar, dizemos, é colocar diante de nós possibilidades. Um pensamento que pensa os games e metaversos a partir de seus pressupostos ontológicos, não somente colabora no sentido de mostrar a importância destes para a cultura hodierna, mas também permite visualizar o panorama da complexidade na qual eles, ao mesmo tempo são possíveis e produzidos. Quando assim agimos, nos engajamos em veredas que mostram caminhos que antes corríamos o risco de deixar escapar.

\section{REFERÊNCIAS BIBLIOGRÁFICAS}


ASCOTT, R. Telematic embrace: visionary theories of art, technology, and consciousness. Los Angeles. Univerity of California Press. ISBN: 0520222946.

BAIRON, S. Texturas sonoras: áudio na hipermídia. São Paulo. Hacker. 2005. ISBN: 8586179442.

BERGSON, H. Matière et Mémoire. Paris. PUF. (Ed. 2004). ISBN: 2130545599.

CAPURRO, R. Contribuições para uma ontologia digital. Texto apresentado no III $^{\circ}$ Colóquio Internacional de Metafísica (CIM), 20-24 de abril, 2009, Natal, Brasil. Disponível em: <http://www.capurro.de/ontologiadigital_pt.html>. Acessado em 10/10/2010.

DELARBE, R. Vivir en la Sociedad de la Información: orden global y dimensiones locales en el universo digital. In: Revista Iberoamericana de Ciencia, Tecnología, Sociedad e Innovación. Número 1 / Septiembre - Diciembre 2001. Monográfico. La Sociedad de la Información.

Disponível em: $<$ http://www.terras.edu.ar/jornadas/30/biblio/30TREJO-DELARBRE-Raul-RevistaIberoamericana.pdf>. Acessado em 01/10/2010.

DELEUZE, G. Cinema-1: A Imagem-movimento. Lisboa. Assírio \& Alvim (1983 - Ed. 2004). ISBN: 9723709589.

. Cinema-2: A Imagem-tempo. São Paulo. Brasiliense (1985 - Ed. 2005). ISBN: 8511220283.

FEENBERG, A. Critical Theory of Technology. Oxford University Press. 1991. ISBN: 0195068556.

FINK, E. Le jeu comme symbole du monde. Paris. Ed. MINUIT. (1960 - Ed. 1966). ISBN: 2707301302.

FONTES, M. Aspectos ontológicos da Web semântica. Dissertação de Mestrado no Programa de Pós-Graduação em Tecnologias da Inteligência e Design Digital. Orientador: Luís Carlos Petry. São Paulo. PUCSP. 2009.

GADAMER, H. G. Verdade e método: traços fundamentais de uma hermenêutica filosófica. Petrópolis. Ed. VOZES. (1960 - Ed. 1999). ISBN: 8532617875.

Verdade e método II. Petrópolis. Ed. VOZES. (1986 - Ed. 2002). ISBN:8532627102.

HEIDEGGER, M. Ser e tempo. Petrópolis. Ed. VOZES. (1927 - Ed. 2006). ISBN: 853263284.

Construir, habitar, morar. (1994a). Disponível em: <http://personales.ciudad.com.ar/M_Heidegger/index.htm.> Acessado em 10/01/2010. A proveniência da arte e a determinação do pensar. (1967). Disponível em: <http://personales.ciudad.com.ar/M_Heidegger/index.htm> Acessado 
em 10/01/2010.

KITTLER, F. A. Gramophone, film, Typewriter. Stanford. Stanford University. 1999. ISBN: 0804732329.

LACAN. J. Seminário 2, O Eu na teoria de Freud e na técnica da psicanálise (1953-1954). Rio de Janeiro. Editora Jorge Zahar. (Ed. 1985). ISBN: 857110316x.

MANOVICH. L. El lenguage de los nuevos medios de comunicaón: la imagen en la era digital. Argentina. Paidós. (2001 - Ed. 2006). ISBN: 9501275639.

MONTAGUE, R. Formal philosophy: selected papers of Richard Montague. New Haven. Yale Univ. Press. 1974. ISBN: 0300015275.

MUSARRA, F. A concepção e criação do caractere tridimensional: metodologia da criação $e$ desenvolvimento de personagens tridimensional para games. Dissertação de Mestrado no Programa de Pós-graduação em Tecnologias da Inteligência e Design Digital. Orientador: Luís Carlos Petry. PUCSP. 2011.

MURRAY, J. Hamlet no holodeck: o futuro da narrativa no ciberespaço. São Paulo. UNESP. (1997 - Ed. 2003). ISBN: 8571394962.

PETRY, A. S. O jogo como condição da autoria e da produção de conhecimento. Tese de Doutorado no Programa de Pós-graduação em Comunicação e Semiótica. Orientadora: Lucia Santaella. São Paulo. PUCSP. 2010.

PETRY, L. C. Topofilosofia: o pensamento tridimensional na hipermídia. Tese de Doutorado no Programa de Pós-graduação em Comunicação e Semiótica. Orientador: Sérgio Bairon. São Paulo. PUCSP. 2003.

Aspectos fenomenológicos da produção de mundos e objetos tridimensionais na hipermídia. Bahia. In: Anais do $15^{\circ}$ Encontro Nacional da ANPAP. 2006. ISBN: 9788560639014. O ciborgue e a arte da hipermídia. Florianópolis. In: $16^{\circ}$ Encontro Nacional da ANPAP. 2007. Dinâmicas Epistemológicas em Artes Visuais. ISBN: 9788561136031. A im@gem pensa:Aspectos quânticos da imagem cibernética. Porto: REVISTA CIBERTEXTUALIDADES, 3. ed. (Universidade Fernando Pessoa.). 2008. ISSN: 16464435

. Some Remarks on Ontological-Cognitive Structures in the Metaverse. In Journal of Virtual Worlds Research. 2010. Volume 2, Number 5: The Metaverse Assembled. Virtual Worlds Institute, Inc. Austin, Texas, USA. ISSN 19418477.

- Por uma ontologia dos metaversos e games. Lisboa: Revista Comunicação \& Linguagens. CECL. Volume 47. (No Prelo). 
PÓVOA, M. Anatomia da Internet: investigações estratégicas sobre o universo digital. Rio de Janeiro. Casa da Palavra. (2000). ISBN: 858722011x.

RUSSELL, B. Lógica y conocimiento. La lógica matemática y su fundamentación em la teoria de los tipos (1908). Madrid, Editorial Taurus. Ed. de 1981. ISBN: 84-306-10480 .

SJÖHLM, C. Kristeva and the political. New York. Routledge. 2005. ISBN: 0415213657.

SCHAAP, R. \& BIDARRA, R. Towards Emotional Characters in Computer Games. In: S.M. Stevens and S. Saldamarco (Eds.) ICEC 2008, LNCS 5309, pp. 167-172, 2008.@ IFIP International Federation for Information Processing 2008. Disponível em: <http://graphics.tudelft.nl/ rafa/myPapers/bidarra.ICEC2008.pdf> Acessado em 10/10/2010.

STEIN, Ernildo. Antropologia filosófica: questões epistemológicas. Ijuí. Editora UNIJUÍ. 2009. ISBN: 9788574297767.

TONÉIS, C. N. A lógica da descoberta nos jogos digitais. Dissertação de Mestrado no Programa de Pós-Graduação em Tecnologias da Inteligência e Design Digital da PUCSP. Orientador: Luís Carlos Petry. São Paulo. PUCSP. 2010.

TURKLE. S. Life on the screen: identity in the age of the internet. New York. SIMON \& SHUSTER PAPERBACKS. 1995. ISBN: 0684833484.

TUTENEL, T., BIDARRA, R., SMELIK, R. \& KRAKER, K. J. The Role of Semantics in Games and Simulations. ACM Computers in Entertainment, Vol. 6, No. 4, Article 57, Publication date: December 2008. Disponível em: <http://graphics.tudelft.nl/ rafa/myPapers/bidarra.ACMCIE08.pdf> Acessado em $10 / 10 / 2010$.

VATTIMO, G. O fim da modernidade: niilismo e hermenêutica na cultura pós-moderna. São Paulo. Martins Fontes. (1985 - Ed. de 2002). ISBN: 853362395x.

VERÍSSIMO, E. Solo de clarineta. Volume 2. São Paulo. Companhia das Letras. (1976 - Ed. de 2007). ISBN: 8535907408.

WANG, H. Reflexiones sobre Kurt Gödel. Madrid. Alianza Editorial. (1987 - Ed. de 1991). ISBN: 8420626902.

Artigo submetido: 13/01/2015

Artigo aprovado: 21/04/2015 